\title{
Fine Coal Fractionation Using a Magnetohydrostatic Separation Process CRADA 91-003, Final Report
}

October 31, 1992

Heechan Cho

R.P. Killmeyer

U.S. Department of Energy

Pittsburgh Energy Technology Center

626 Cochrans Mills Road

Pittsburgh, PA 15236

and

Intermagnetics General Corporation

P.O. Box 566

Guilderland, NY 12084 


\section{Disclaimer}

This report was prepared as an account of work sponsored by an agency of the United States Government. Neither the United States Government nor any agency thereof, nor any of their employees, makes any warranty, express or implied, or assumes any legal liability or responsibility for the accuracy, completeness, or usefulness of any information, apparatus, product, or process disclosed, or represents that its use would not infringe privately owned rights. Reference herein to any specific commercial product, process, or service by trade name, trademark, manufacturer, or otherwise does not necessarily constitute or imply its endorsement, recommendation, or favoring by the United States Government or any agency thereof. The views and opinions of authors expressed herein do not necessarily state or reflect those of the United States Government or any agency thereof. 


\section{DISCLAIMER}

Portions of this document may be illegible electronic image products. Images are produced from the best available original document. 


\section{Fine Coal Fractionation Using a Magnetohydrostatic Separation Process CRADA 91-003, Final Report}

October 31, 1992

Heechan Cho

R.P. Killmeyer

U.S. Department of Energy Pittsburgh Energy Technology Center 626 Cochrans Mills Road

Pittsburgh, PA 15236

and

Intermagnetics General Corporation

P.O. Box 566

Guilderland, NY 12084 
Fine Coal Fractionation Using a Magnetohydrostatic Separation Process

The magnetohydrostatic separation (MHS) process uses a magnetic fluid which has the ability to float a submerged particle in a magnetic field. Therefore, it is possible to separate particles of differing density. Intermagnetics General Corp. has developed the Magstream separator which utilizes this process for mineral separation. Laboratory test work showed a potential of this process for coal cleaning, yet further research is still required for fine coal cleaning and large-scale application. The objective of the current project was to develop a technique for laboratory gravity fractionation of coal using MHS. This application can replace the conventional sink/float technique for coal washability studies, and has advantages in that: (1) a wide range of separation densities can easily be obtained, (2) it is operated on continuous basis and (3) the magnetic fluid is non-toxic. Also, the production of large quantities of relative density fractions is possible in a short time. Tests were conducted to evaluate the technical feasibility of this application in cooperation with IGC.

\section{Familiarization of Equipment}

IGC provided DOE with the magnetic fluid (a water-based suspension of colloidal magnetite containing a lignosulfonate dispersant) and technical support for the initiation of the project. A demonstration was given by IGC personnel in December, 1991 at DOE/PETC during which proper operational procedures of the DOE Magstream separator were explained. The whole procedure was video taped for future reference.

The equipment is designed to separate particles based on relative density differences by balancing two counteracting forces - buoyancy force exerted by the magnetic fluid and centrifugal force induced by the rotation of fluid. The buoyancy force is determined by the product of the magnetic field gradient and the magnitude of the fluid magnetization. The centrifugal force is controlled by the rotational speed of the fluid. Therefore, for a given magnetic field and a concentration of magnetic fluid, the separation density can easily be set by adjusting the rotational speed. Although changes in magnetic field will also affect the relative density, this option is not available for this particular unit due to the installation of a permanent magnet. Another controllable variable for the process is flow rate of fluid, which is governed by the time required for a particle to separate before it escapes the separation chamber.

\section{Tests}

Preliminary tests were conducted using a coal/quartz mixture. Since the maximum relative density of the test coal was below 2.5 whereas that of quartz is 2.65 , the two materials were separated by setting the cut density at 2.5. Products were then examined visually to determine the quality of separation. However, the separation was not as efficient as expected due to the hydrophobic nature of coal. By adding a wetting agent (Aerosol OT) and employing an agitator in the mixing tank, the separation was improved. With proper settings of operational variables, a nearly perfect separation of coal/quartz was obtained. 
Washability tests were conducted on an Upper Freeport seam coal using the Magstream separator. The relative density of separation was increased by decreasing the rotational speed. Due to the mechanical configuration of the equipment, particle size is limited to less than 28 mesh. Previous work with the Magstream separator has shown that separation efficiency decreases below 100 mesh. Therefore, the coal samples were sized into two size fractions $-28 \mathrm{~m} \times 100 \mathrm{~m}$ and $100 \mathrm{~m} \times 200 \mathrm{~m}$ and the tests were conducted separately.

\section{Results}

Table 1 shows the results for the $28 \mathrm{~m} \times 100 \mathrm{~m}$ fraction. It can be seen that the yields from the magnetic fluid tests were consistently lower than those from the conventional sink/float analysis. However, the cumulative float data follows a typical washability trend up to 1.6 relative density where the yield monotonically increases as the relative density increases. Ash analyses of the relative density fractions revealed that a proper separation occurred such that the ash content of the float fraction increased as the yield increased. Above 1.6 relative density, the yield did not increase further but fluctuated, indicating that there possibly was a lower rpm limit for the particular concentration of the magnetic fluid used for these tests. After completing the separations, a considerable amount of coal particle agglomerates were found inside the separation chamber. The variation in the calculated feed ash and lower yield may be attributed to this material.

For the $100 \mathrm{~m} \times 200 \mathrm{~m}$ fraction, the wettability made it difficult to feed the material. The particles tended to accumulate on the liquid surface unless the feed rate was reduced greatly. Therefore, a wet feeding method was used in which a slurry of coal particles and magnetic fluid was prepared and pumped to the separator. These results are shown in Table 2. It can be seen that the wet feeding method produced a different result. Also, the calculated ash content of the feed was not consistent, which again may be attributed to the agglomerated particles remaining inside the separation chamber. Later, it was found that the rotor inside the separator did not function properly. Consultation with IGC indicated that this might have been responsible for the tendency of the coal particles to remain inside the separation chamber. The rotor was sent to IGC, repaired, and returned, although there was insufficient time to have it reinstalled into the Magstream unit and to conduct additional testing. Due to personnel changes and the work loads of both organizations, it was mutually agreed to terminate the CRADA. In conclusion, it seems that the interface phenomena between coal particles and the magnetic fluid may have also contributed to the separation problem and should be examined. In addition, it appears that there may be some inherent weaknesses in the process with regard to the forces available to separate such fine particles with relatively small density differences compared to minerals. Further investigation is needed for proper application of this process to the float/sink separation of coal. 
Table 1. Density fractionation of Upper Freeport Seam Coal $(28 \mathrm{~m} \times 100 \mathrm{~m})$

\begin{tabular}{|c|c|c|c|c|c|c|}
\hline & \multicolumn{2}{|c|}{ Conven. } & Magfluic & \multicolumn{3}{|c|}{ Ash Content } \\
\hline $\mathrm{om}$ & sp.gr. & $w t \%$ & wt $\%$ & cum.flt. & cum.snk. & feed(Cal.) \\
\hline 10 & 1.3 & 43.35 & 13.48 & 5.49 & 8.82 & 8.37 \\
\hline 353 & 1.4 & 75.80 & 49.67 & 5.63 & 13.04 & 11.88 \\
\hline 316 & 1.5 & 86.14 & 64.10 & 7.57 & 21.86 & 12.70 \\
\hline & 1.6 & 92.16 & 70.63 & 13.63 & 33.02 & 19.32 \\
\hline & 1.7 & 96.68 & 60.67 & 9.37 & 15.58 & 11.75 \\
\hline & 2.0 & 97.86 & 69.09 & 10.44 & 15.85 & 12.11 \\
\hline
\end{tabular}

Table 2. Density fractionation of Upper Freeport Seam Coal $(100 \mathrm{~m} \times 200 \mathrm{~m})$

\begin{tabular}{lllccc} 
& \multicolumn{5}{c}{ Ash Content } \\
rpm & sp.gr. & $\frac{w+\%}{31.71}$ & $\frac{\text { cum.flt. }}{3.94}$ & $\frac{\text { cum.snk. }}{8.06}$ & $\frac{\text { feed(Cal.) }}{6.75}$ \\
410 ,dry & 1.3 & -3.71 & 18.04 & 8.69 \\
353 ,dry & 1.4 & 63.39 & 5.67 & 12.18 & 8.00
\end{tabular}

